\title{
A Different Comment on Understanding
}

\author{
Fang WANG \\ Foreign Languages Teaching and Research Dept., Luoyang Normal University, \\ Luoyang, China \\ 2456745@163.com
}

Keywords: Heidegger, Understanding, Interpretation, Fore-structure.

\begin{abstract}
As Heidegger tells us, "when tradition becomes master, it does so in such a way that what it 'transmits' is made so inaccessible, proximally and for the most part, that it rather becomes concealed. Tradition takes what has come down to us and delivers it over to self-evidence; it blocks our access to those primordial 'sources' from which the categories and concepts handed down to us have been in part quite genuinely drawn" (BT, 43). So, to go back 'to the things themselves!' is very significant and indispensable in unconcealing the real 'sources'.
\end{abstract}

\section{Introduction}

Can we infer from Long's siding with the instructor-like reader that he is free from bodily responses to what he reads? Is it true that English Literature compiled by Long is written fully in the instructor's style of "analysis" and "exact description" only? No. When Long reads a particular poem he always knits the words of "simple enjoyment and appreciation" into his brilliant analysis. Why does Long seem to impose the instructor's reading style upon the child then? The two kinds of understanding of the shell in the story are contradictory to each other since one is marked by bodily response and the other is theoretical cognition. But how can the child possess the instructor's understandability? Isn't it that Long wants to substitute the child's somatic response and states-of-mind with his own? When we raise such questions should we not forget that the child's responses to the shell in the above story are "wonder", "strange", and "delight", which are also understandings of the shell fundamentally grounded in the child's primary understanding of being, although they are unthematic, dim, vague, fluctuating, and indefinite? No, otherwise we don't feel that it is necessary to develop Long's story of understanding so and so. It is Long who keeps his understanding of being in terms of being-in-the-world in blindness so much so that he can but insightfully agree to and recommend what the instructor's understanding of being of the shell presents.

\section{The Forgetfulness of Primordial Understanding in the Theoretical Explanation}

In the above story, Long's blindness in the child's a priori understanding of state-of-mind is set off by his insight in the instructor's theoretically universalized reading of the shell. Undoubtedly, the child himself is not self-contradictory in his 
intelligible behavior towards the shell, since in his given, externally determined practical situation what he proximally has is an unreflexive understanding of himself in terms of the kind of being of entities which supports and directs his specific comportment. Such words as "wonderful", "delightful", and "strange, low, melodious", etc. are already the kind of ontical understandings of the shell, which are so near to the shell in virtue of somatic experience and states-of-mind. By suppressing the child's somatic encountering-reading of the shell for the sake of establishing the instructor's theoretical subject-object split reading only betrays Long's forgetfulness of human being's primary understanding which is co-original with being-in-the-world. Such kind of forgetfulness of primordial conditions of possibility of understanding is also seen in the earlier story about Polydamas and Hector when they try to understand/interpret the portentous meaning of the bird sign.

For Polydamas forgets his reservation he adopts about his identity as a layman when he indulges himself into interpreting/translating the bird sign. Hector at first insists on his disbelief in any portent of the bird sign on the ground of being personally conferred with the god - Iris's message, completely forgets the temporal validity of that message later. Therefore, ontologically speaking, Long, Polydamas, and Hector are not differentiated in the sense of forgettableness; each of them has undergone an experience of deconstruction far beyond their awareness.

Now let us the leave the instructor's reading of the shell alone to have another look at the child's point of view of the shell so as to existentially restitute that which ontologically directs and governs the child's comporting himself towards the entity-shell.

Our only clue for this problem is Long's third-person indirect report of the child's responding to the shell, obviously edited by Long. Even from this survival we can still restitute the child's basic structure of interpretation of the shell in a simple formula: to see (hear, feel, or interpret) something (it) as something (a shell) is to see something (it) which has already been understood in advance as the thing (the shell) it is; to see something as something is to see something understandingly so and so or such-and-such. To see means to be able to see, and this ability is nothing but the a priori understanding of being in general which in itself holds everything within the world in the form of "it". Since "To see means to be able to see", the "seeing" itself is already a kind of understanding which is grounded in the primary understanding of being. Thus to see means to see understandingly, its ability of "seeing" comes from the source of the primary understanding of being. The first "something" in the formula "to see something as something" should be the "something" which stands for the "it" in the primary understanding of being, and accordingly the second "something" should be the thematized or interpreted "it" in an ontical form of some particular entities, say, the shell. All these points will be further expounded in detail along the development of the thesis. To treat the child's response to the shell in this way, we have moved out of Long's blindness into Heidegger's existential analytics of Dasein (the human being). It then becomes necessary to introduce some relevant Heidegger's terminology to our investigation. 


\section{Heideggerian Sense of Understanding}

we know that Dasein is just a common man, an everyone, an individual person, a human being, it can be used in the plural as well as in the singular form. When indicated by the personal pronouns, Dasein is usually represented with the neutral pronoun 'it' (or rarely "they"). We will follow suit.

According to Heidegger, Dasein's most basic state is its "being-in-the-world", as can been seen in "Being-In-The-World In General As The Basic State Of Dasein", the title of Chapter Two, Part One of his book Being and Time. This basic structure determines Dasein as "an entity which, in its very Being, comports itself understandingly towards that Being" (BT, 78). That is to say, Dasein is thus encompassed by its very being in which it understandingly circulates from its being to its being. Or to put it simply, Dasein itself is constituted by this circular understanding of being (to be discussed later). Here, one is likely to question the child's somatic response to the shell in our earlier story on whether his understanding of being is in accordance with Heidegger's analytics of Dasein, for it seems that Heidegger's conception of Dasein is an adult, fully grown, being of age, well-weathered, and experienced. Yet this objection is pointless, because the determination of Dasein as it is does not mean the sum of those attributes or properties put together, but its existence as being-in-the-world always shows itself in the form of understanding of being. Dasein's essence lies in its existence, it possesses no whatness but only thatness as a mode of its existence in the world. In the sense of existence, Dasein can only be inquired with such question "Who is Dasein?" rather than "What is Dasein?" Those attributes cited above are only appearances covering up the real existence of Dasein. In Section 10, Chapter One, Part Two, of Being and Time, under the title "The Existential Analytic and the Interpretation of Primitive Dasein. The Difficulties of Achieving a 'Natural Conception of the World' ", we read these sentences:

Even primitive Dasein has possibilities of a Being which is not of the everyday kind, and it has a specific everydayness of its own. To orient the analysis of Dasein towards the 'life of primitive peoples' can have positive significance as a method because 'primitive phenomena' are often less concealed and less complicated by extensive self-interpretation on the part of the Dasein in question. Primitive Dasein often speaks to us more directly in terms of a primordial absorption in 'phenomena' (taken in a pre-phenomenological sense). A way of conceiving things which seems, perhaps, rather clumsy and crude from our standpoint, can be positively helpful in bringing out the ontological structures of phenomena in a genuine way (BT, 76).

It is obvious that the above quotation has an intrinsic connection with the story of understanding related to the child who intelligibly comports himself to the shell. In terms of understanding of being, the child in Long's story and Dasein in Heidegger's philosophy are inter-explicative and inter-illustrative: In this quotation, isn't it possible that a primitive Dasein is taken as a child whose understanding of being is less concealed and less complicated, who speaks more directly to us? Are we not already familiar with the phraseology 'the childhood of mankind'? Indeed, the child in Long's story and the primitive Dasein in Heidegger's philosophy are commensurable because Heidegger's Dasein is neither specially fixed at a particular 
time nor a particular person but rather signifies the most fundamentally existential structure which is such-and-such all the time despite of different levels of culture, for "even when that Dasein is active in a highly developed and differentiated culture" it is still confined to its "Being-in-the-world" (ibid).

By now the motivation in citing the story of "The Shell and the Book" in illustration of the problem of understanding of being should be clear. Generally speaking, Heidegger's conception of understanding is not completely understood in an ordinary manner. For Heidegger, "Understanding is nothing necessarily cognitive, but rather the entire scope of our ability to make sense of things by availing ourselves of them competently, even if unreflectively, in practice" (HA, 18-19). Understanding is like Dasein itself, whose essence "lies in its 'to be'. Its Being-what-it-is must, so far as we can speak of it at all, be conceived in terms of its Being" (BT, 67). Like Dasein, understanding as a mode of being is equiprimordial with its being-in-the-world; its ability is thus constituted before the cognitive dichotomy between subject and object. According to Heidegger, "Understanding is conceived not as something to be possessed but rather as a mode or constituent element of being-in-the-world. It is not an entity in the world but rather the structure in being which makes possible the actual exercise of understanding on an empirical level. Understanding is the basis of for all interpretation; it is co-original with one's existing and is present in every act of interpretation. Understanding is thus ontologically fundamental and prior to every act of existing" (Palmer, 1969: 131). The author of this paper feels it advisable to orient his dissertation in conformity with Heidegger's analytics of Dasein in the method of his phenomenology. For the sake of disclosing the most fundamental structure of Dasein, Heidegger must first of all unconceal and open the various culturalized crusts survived in the name of tradition and lay bare the authentic conditions of possibility of Dasein's understanding of being which has already been not only thickly concealed but also deeply buried in forgetfulness. For in our average everydayness of existence, it is the tradition that not only deviates us from the genuine track to the real meaning of our understanding of being but also makes us believe in what we have taken over from the hands of tradition is as certain and self-evident and thus forget what the authentic conditions of our understanding of being. As Heidegger tells us, "when tradition becomes master, it does so in such a way that what it 'transmits' is made so inaccessible, proximally and for the most part, that it rather becomes concealed. Tradition takes what has come down to us and delivers it over to self-evidence; it blocks our access to those primordial 'sources' from which the categories and concepts handed down to us have been in part quite genuinely drawn" (BT, 43). So, to go back 'to the things themselves!' is very significant and indispensable in unconcealing the real 'sources'.

\section{Conclusion}

To go back to the primordial "sources" for the understanding of being is to go back "to the things themselves". We will then take the child's somatic response to the shell as an instance to look into what Heideggerian sense of understanding is. In so doing, it is not only a shortcut in questing for the primordial "sources" of understanding of 
being but also in agreement with Heidegger's description about the primitive Dasein's understanding of being.

\section{References}

[1] Culler, Jonathan. On Deconstruction: Theory and Criticism after Structuralism. Beijing: Foreign Language Teaching and Research Press, 2004.

[2] Davis, Kathleen. Deconstruction And Translation. Shanghai: Shanghai Foreign Language Education Press, 2004.

[3] Derrida, Jacques. Writing and Differences. Alan Bass (trans.) Britain: Routledge and Kegan Paul Ltd., 1978.

[4] Ferraris, Maurizio. History of Hermeneutics, Luca Somigli (trans.) New Jersey: Humanities Press, 1996.

[5] Gutt, Ernst-August. Translation and Relevance-Cognition and Context. Shanghai: Shanghai Foreign Language Education Press, 2004.

[6] Heidegger, Martin. Kant and the Problem of Metaphysics. R. Taft (trans.) Bloomington: Indiana University Press, 1990. 